\title{
A Tertiary Care Hospital-based Study of Various Skin Manifestations in Diabetes Mellitus Patients: Skin as a Clinical Marker of Diabetes Mellitus
}

\author{
Purshottam L Gupta ${ }^{1}$, Kishor Singh ${ }^{2}$, Ganpat Devpura ${ }^{3}$
}

\begin{abstract}
Introduction: Incidence of skin manifestations in diabetes mellitus (DM) varies from 11.3 to $70.6 \%$ and may manifest once the primary disease has already developed, but may also occur coincidently with its onset or may even precede DM in some of the cases. Our study is an attempt to analyze the pattern of various types of skin manifestations seen in DM.

Aims and objectives: To study and analyze the various skin manifestations in patients of DM.

Materials and methods: Two hundred patients of DM were enrolled. A detailed history was taken, investigations like preprandial and postprandial capillary plasma glucose and $\mathrm{HbA} 1 \mathrm{c}$ were done. Diabetes was considered controlled when preprandial capillary plasma glucose $3.9-7.2 \mathrm{mmol} / \mathrm{L}$ (70-130 mg/dL), postprandial capillary plasma glucose $<180 \mathrm{mg} / \mathrm{dL}$, and $\mathrm{HbA} 1 \mathrm{c}<7.0 \%$.

Results: Infections were the commonest skin manifestation present in a total of $81 \%$ of patients ( $56 \%$ fungal, $19 \%$ bacterial, and $6 \%$ viral) followed by conditions associated with DM present in $67 \%$ of patients (skin tag $33 \%$ was the commonest). Miscellaneous skin conditions were present in $62 \%$ of patients (discoloration of nails was the commonest $11 \%$ ).

Conclusion: Various skin manifestations may appear early and remain undetected till DM is diagnosed. The majority of patients do not take regular treatment and follow dietary restrictions in early diabetes leading to a persistent hyperglycemic state which predisposes to infections and other skin manifestations. The presence of easily visible skin manifestations can heighten the suspicion for early diagnosis of DM and thus, may very well be taken as a clinical marker of DM.

Keywords: Diabetes mellitus, Skin as clinical marker of DM, Skin manifestations.

Journal of Mahatma Gandhi University of Medical Sciences \& Technology (2021): 10.5005/jp-journals-10057-0142
\end{abstract}

\section{INTRODUCTION}

The World Health Organization (WHO) describes diabetes mellitus (DM) as a chronic, multisystem disorder with chronic hyperglycemia, disturbances of fat, protein, and carbohydrate metabolism because of disturbance in either insulin action or secretion or both.

Common symptoms in DM are polyuria, weight loss and blurring of vision, coma, and even death can occur due to acute complications like ketoacidosis ${ }^{1}$ and a non-ketotic hyperosmolar state. ${ }^{2}$ India has the world's largest diabetic population which is approximately 51.8 million. . $^{3,4}$

Classification of DM: ${ }^{1}$

- Diabetes mellitus type-1

- Diabetes mellitus type-2

- Other specific types of diabetes

- Gestational diabetes mellitus (GDM).

\section{Cutaneous Manifestations}

Acute metabolic disturbances and chronic degenerative complications of DM also affect the skin. The incidence of skin manifestations associated with DM varies from 11.3 to $70.6 \% .^{5}$ The skin manifestations seen in DM mostly appear either once the primary disease has already developed, or it may also occur coincidently with its onset or may even precede DM by many years in many of the cases.

Classification of cutaneous manifestations of DM: ${ }^{6}$

- Cutaneous infections in DM

- Cutaneous associations of DM

\footnotetext{
1,3 Department of General Medicine, NIMS Medical College, Jaipur, Rajasthan, India

${ }^{2}$ Department of Dermatology, Venereology and Leprosy, NIMS Medical College, Jaipur, Rajasthan, India

Corresponding Author: Purshottam L Gupta, Department of General Medicine, NIMS Medical College, Jaipur, Rajasthan, India, Phone: +91 9414447233, e-mail: drguptapl@gmail.com

How to cite this article: Gupta PL, Singh K, Devpura G. A Tertiary Care Hospital-based Study of Various Skin Manifestations in Diabetes Mellitus Patients: Skin as a Clinical Marker of Diabetes Mellitus. J Mahatma Gandhi Univ Med Sci Tech 2021;6(1):10-14.

Source of support: Nil

Conflict of interest: None
}

- Cutaneous manifestations of complication of DM

- Cutaneous reactions to the treatment of DM.

At times, the skin manifestations can be the first presenting sign of DM; hence, our study is an attempt to analyze the pattern of various types of skin manifestations seen in DM.

\section{Aims and Овjectives}

To study and analyze the skin manifestations in patients of DM.

\section{Materials and Methods}

The present study was carried out in the outpatient Departments of NIMS Medical College; a tertiary care hospital in Jaipur. A total

() The Author(s). 2021 Open Access This article is distributed under the terms of the Creative Commons Attribution 4.0 International License (https:// creativecommons.org/licenses/by-nc/4.0/), which permits unrestricted use, distribution, and non-commercial reproduction in any medium, provided you give appropriate credit to the original author(s) and the source, provide a link to the Creative Commons license, and indicate if changes were made. The Creative Commons Public Domain Dedication waiver (http://creativecommons.org/publicdomain/zero/1.0/) applies to the data made available in this article, unless otherwise stated. 
of 200 consecutive patients of DM (type 1 and 2) attending the Department of Medicine and Dermatology were enrolled.

\section{Ethics}

Patients' confidentiality was maintained and informed consent was taken.

\section{Inclusion Criteria}

- Diagnosed cases of DM willing to participate in the study.

\section{Exclusion Criteria}

- Patients $<15$ years of age.

- Patients with GDM.

- Unwilling patients.

Detailed history with special reference to age, sex, rural/urban background, BP, smoking, alcohol intake, duration of diabetes, type of diabetes, type of treatment taken, complications, and family history was taken. A complete general, physical, systemic, and dermatological examination was carried on each patient.

Investigations like hemoglobin, total leukocyte count, differential cell count, preprandial capillary plasma glucose, postprandial capillary plasma glucose, complete urine examination, and $\mathrm{HbA} 1 \mathrm{c}$ were done in each patient. Assessment of glycemic control (DM) was done by measuring preprandial capillary plasma glucose, postprandial capillary plasma glucose, and $\mathrm{HbA1C}$ and DM was considered to be controlled when preprandial capillary plasma glucose $3.9-7.2 \mathrm{mmol} / \mathrm{L}$ (70-130 $\mathrm{mg} / \mathrm{dL}$ ), postprandial capillary plasma glucose $<180 \mathrm{mg} / \mathrm{dL}$, and $\mathrm{HbA} 1 \mathrm{c}<7.0 \%$ were measured.

\section{Results}

The study group included 200 patients with DM with skin manifestations. The age group varied from 20 to 79 years with a mean age of 52 years and SD of 10.52 years. The minimum age was 25 years and the maximum was 75 years. The maximum number of patients was in 50-59 years (32\%) of age group, followed by age group $40-49$ years (27\%). Fifty-five percent of the patients were male and $45 \%$ were females with male to female ratio of 1.2:1.

Out of 200 patients, $73 \%$ of the patients belonged to a rural background while $27 \%$ were from an urban background.

The maximum no. of patients (48\%) were from lower socioeconomic status, followed by $38 \%$ from middle socioeconomic and $14 \%$ were from upper socioeconomic status.

The maximum no. of patients were housewives (51\%), followed by retired persons (19\%) and businessman (16\%). Miscellaneous group (14\%) constituted of priest, tailor, policeman, astrologer, Anganwadi worker, etc.

Fifty percent of patients were overweight, $26 \%$ were of normal weight, $21 \%$ patients were obese, and the remaining $3 \%$ were underweight (Table 1).

Ninety-two percent of the patients had type 2 DM while only $8 \%$ of the patient was that of type 1 DM.

Twenty-one percent of the patients were smokers, $13 \%$ were alcoholics, and $30 \%$ were hypertensive.

The maximum no. of patients (50\%) had a duration of diabetes between 1 years and 5 years, 21\% between 6 years and 10 years duration, while $19 \%$ had duration $<1$ year, and only $10 \%$ patients were having diabetes $\geq 16$ years of duration.
The maximum no. of patients (60) were on oral hypoglycemic drugs, while $33 \%$ of the patients were on combination therapy, i.e., insulin and oral hypoglycemic. Seven percent of the patients were not on any treatment for DM.

Fifty-three percent of the patients were on regular treatment, while $40 \%$ were irregular treatment and $7 \%$ were on no treatment. Out of $53 \%$ patients on regular treatment, $52.8 \%$ patients had controlled diabetes $(\mathrm{HbA} 1 \mathrm{c} \leq 7)$ whereas among patients on irregular treatment (40\%) only $19.5 \%$ of patients had controlled diabetes. Seven percent of patients who did not take any treatment had uncontrolled diabetes $(\mathrm{HbA1c} \geq 8$ ) (Table 2).

Skin infections were the commonest manifestations present in $81 \%$ of patients, followed by the conditions associated with DM, which were present in $67 \%$ of patients, miscellaneous skin conditions were present in $62 \%$ of patients, and none of the patients had complications due to treatment of DM.

Most of the patients in the infection group had more than one manifestation. Out of 200 patients, $56 \%$ had a fungal infection, $19 \%$ had bacterial infections, and $6 \%$ had viral infections. None of the patients had parasitic infestation (Table 3). Out of 162 patients, 25 patients had a single infection of 137 patients had more than one infection.

The skin conditions associated with DM were present in $67 \%$ of patients. Among the skin conditions, skin tag was the most common (33\%), followed by cherry angioma in $6 \%$, xerosis in $5 \%$, etc. (Table 4 ).

Miscellaneous cutaneous findings were present in $62 \%$ of total cases. Discoloration of the nail was the commonest (11\%), followed by decrease hair over lower legs and foot in $10 \%$, eczemas in $10 \%$, psoriasis in $5 \%$, etc. (Table 5).

Skin infections were the commonest complications (46\%) in inadequate and poorly controlled diabetes (i.e., HbA1c $\geq 7$ ). Fungal infections were the commonest (56\%) among infections followed by bacterial (19\%) and viral (6\%) in all these groups. Diabetesassociated complications and miscellaneous skin conditions were also more frequent among inadequate and poorly controlled diabetes, i.e., 72.4 and $51.7 \%$, respectively.

The majority of patients had $3(26 \%), 4(25 \%)$, and $2(21 \%)$ skin manifestations followed by 1 (12\%), 5 (9\%), and $\geq 6$ (7\%) skin manifestations per patients.

\section{Discussion}

Diabetes mellitus is the most common endocrine disorder which involves the skin. Many skin disorders are associated with DM. Dermatological signs of DM mostly appear once the primary disease has already developed but may also appear coincidently with its onset or even precede DM by years.

In the present study, the majority of patients were in the age group of 50-60 years (32\%). This is in agreement with various studies done by Sawhney et al., ${ }^{7}$ Mahajan et al., ${ }^{8}$ Nigam and Pande, ${ }^{9}$ and Nawaf et al. ${ }^{10}$ The skin manifestations increase with age, duration, as well as the level of blood sugar control and severity of DM.

Males (55\%) outnumbered females (45\%) in our study, which is in agreement with studies done by Sawhney et al. ${ }^{7}$ and Rao and Pai. ${ }^{11}$ However, Romano et al., ${ }^{12}$ Nigam and Pande, ${ }^{9}$ Al Mutairi, ${ }^{13}$ Mahajan et al., ${ }^{8}$ and Bhat et al. ${ }^{14}$ reported a higher incidence of dermatological manifestations in female diabetic patients. This may be due to the fewer number of females in our study. 
Table 1: BMI $\left(\mathrm{kg} / \mathrm{m}^{2}\right)$

\begin{tabular}{llcccc}
\hline & & \multicolumn{3}{c}{ Number of patients $(n=100)$} & Total \\
\cline { 3 - 5 } S.no. & BMI & Male & Female & 6 & 3 \\
\hline 1 & $\leq 18.50$ (underweight) & 2 & 4 & 52 & 26 \\
2 & 18.50 to 24.99 (normal) & 26 & 26 & 100 & 50 \\
3 & 25 to 29.99 (overweight) & 62 & 14 & 42 & 21 \\
4 & $\geq 30$ (obese) & 28 & & 14 \\
\hline
\end{tabular}

Table 2: Control and compliance of treatment of diabetes mellitus

\begin{tabular}{llccr}
\hline & & \multicolumn{2}{c}{ Diabetic control } & \\
\cline { 3 - 4 } & & Controlled & Uncontrolled & Total \\
\hline Compliance & Regular & $56(52.8 \%)$ & $50(47.2 \%)$ & 106 \\
of treatment & Irregular & $14(19.5 \%)$ & $66(82.5 \%)$ & 80 \\
of DM & No treatment & $2(19.5 \%)$ & $14(100 \%)$ & 14 \\
Total & & $72(36 \%)$ & $128(64 \%)$ & 200 \\
\hline
\end{tabular}

It could also be because of lack of awareness, illiteracy, and negligence on the part of female patients as well as socioeconomic backwardness.

In the index study, the majority of the patients had uncontrolled diabetes (64\%) which is comparable with studies by Sawhney et al. ${ }^{7}$ (97\%), Yosipovitch et al. ${ }^{15}$ (71\%), Nigam and Pande ${ }^{9}(52 \%)$, Bhat et al. ${ }^{14}$ (55\%), and Ahmed et al. ${ }^{16}$ (94\%). Poorly controlled DM, the severity of disease, and the duration of illness increase the chances of complications.

In the present study, among the various dermatological manifestations, infections were the most frequent dermatological manifestations (81\%) followed by other dermatological conditions associated with DM (67\%) and miscellaneous skin findings (62\%). Almost similar findings were reported. Studies by Mahajan et al. ${ }^{8}$ (54\%), Nigam and Pande ${ }^{9}(26 \%)$, Bhat et al. ${ }^{14}(34 \%)$, and Al Mutairi et al. ${ }^{13}(68 \%)$.

Fungal infections (56\%) were the commonest infections followed by bacterial (19\%) and viral (6\%). However, in similar studies by Yosipovitch et al. ${ }^{15}$ and Bhat et al., ${ }^{14}$ the incidences of fungal infections reported were 32 and $34.34 \%$, respectively.

Among the skin conditions associated with DM, skin tags were the commonest and were present in $33 \%$ of patients in our study. Various similar studies by Kahana et al. ${ }^{17}$ and Thappa ${ }^{18}$ observed that skin tags present in 26.3 and $62.85 \%$ of the cases, respectively.

Acanthosis nigricans was present in $4 \%$ of the patients in our study, Mahajan et al., ${ }^{8}$ Bhat et al., ${ }^{14}$ Al Mutairi et al., ${ }^{13}$ and Ahmed et al. ${ }^{16}$ reported an almost similar incidence of acanthosis nigricans in their study 3, 5.3, 4.7, and 2.8\%, respectively. Acanthosis nigricans and skin tags are dermatological manifestations of DM that may precede the occurrence of DM. A high level of insulin acts on insulinlike growth factor receptors (IGF) which resulted in the development of acanthosis nigricans.

In the present study, diabetic foot ulcer was present in 3\% of the patients. Almost similar findings were reported by Puri et al., $2012^{19}$ in their study in $2 \%$ of patients of DM.

In the present study, $12,21,26,25,9$, and $7 \%$ of patients had $1,2,3,4,5$, and $\geq 6$ cutaneous manifestations, respectively. While almost similar observations were made by Goyal et al. ${ }^{20}$ in their study $20,20,12,16,14$, and $2 \%$ of patients had $1,2,3,4,5,6$, and 7 cutaneous manifestations, respectively.
Table 3: Skin infections/infestations

\begin{tabular}{lrrrr}
\hline & \multicolumn{3}{c}{ Number of patients $(n=162)$} & \\
\cline { 2 - 4 } & Male & Female & Total & Percentage \\
\hline (1) Fungal & 52 & 60 & 112 & 56 \\
(A) Dermatophytosis & 37 & 35 & 72 & 36 \\
T. corporis & 18 & 16 & 34 & 17 \\
T. cruris & 14 & 14 & 28 & 14 \\
Onychomycosis & 1 & 3 & 4 & 2 \\
T. pedis & 2 & 2 & 4 & 2 \\
T. unguium & 2 & 0 & 2 & 1 \\
(B) Candidiasis & 15 & 25 & 40 & 20 \\
Candidal & 12 & 0 & 12 & 6 \\
balanoposthitis & & & & \\
Vaginal candidiasis & 0 & 12 & 12 & 6 \\
Cutaneous & 0 & 8 & 8 & 4 \\
candidiasis & & & & \\
Candial & 3 & 2 & 5 & 4 \\
paronychia & & & & \\
(2) Bacterial & 18 & 20 & 38 & 19 \\
Folliculitis & 8 & 8 & 16 & 8 \\
Furunculosis & 6 & 10 & 16 & 8 \\
Carbuncle & 2 & 2 & 4 & 2 \\
Foot ulcer & 2 & 0 & 2 & 1 \\
(3) Viral & 4 & 8 & 12 & 6 \\
Herpes simplex & 2 & 4 & 6 & 3 \\
Herpes zoster & 3 & 3 & 6 & 3 \\
\hline
\end{tabular}

The number of skin manifestations in our study was comparatively higher because a large percentage (64\%) of our patients had uncontrolled diabetes. Poor dietary control, food habits, illiteracy, poor hygiene, climatic conditions, rural background, and socioeconomic backwardness may be the additional factors.

\section{Conclusion}

Diabetes mellitus is a multisystem disease and skin, is also not spared by its complications. These may either appear early or remain undetected till DM is diagnosed. The majority of patients do not take regular treatment and follow dietary restrictions in early diabetes leading to a persistent hyperglycemic state which predisposes to infections. The advanced glycosylation end product (AGE) may lead to other complications like microangiopathy, neuropathy, etc., which appear late. The presence of skin manifestations (which are easily visible) can heighten the suspicion for DM enabling early diagnosis of DM and thus be very well taken as a clinical marker for DM. 
Table 4: Skin conditions associated with diabetes mellitus

\begin{tabular}{rlrrrr}
\hline & & \multicolumn{3}{c}{ Number of patients $(n=134)$} \\
\cline { 3 - 6 } S.no. & & Male & Female & Total & Percentage \\
\hline 1 & Skin tag & 32 & 34 & 66 & 33 \\
2 & Cherry angioma & 4 & 8 & 12 & 6 \\
3 & Xerosis & 8 & 2 & 8 & 5 \\
4 & Acanthosis nigricans & 6 & 2 & 8 & 4 \\
5 & Generalized pruritus & 4 & 4 & 8 & 4 \\
6 & Xanthelasma palpebrarum & 2 & 6 & 6 & 4 \\
7 & Diabetic dermopathy & 2 & 6 & 4 & 3 \\
8 & Yellow discoloration of skin & 3 & 3 & 2 & 2 \\
9 & Diabetic thick skin & 2 & 2 & 1 & \\
10 & Rubeosis faciei & 1 & 1 & 2 & 1 \\
\hline
\end{tabular}

Table 5: Miscellaneous skin conditions

\begin{tabular}{|c|c|c|c|c|c|}
\hline \multirow[b]{2}{*}{ S. no. } & & \multicolumn{3}{|c|}{ Number of patients $(n=124)$} & \multirow[b]{2}{*}{ Percentage } \\
\hline & & Male & Female & Total & \\
\hline 1 & Discoloration of nail & 11 & 11 & 22 & 11 \\
\hline 2 & Decreased hair on lower leg and foot & 12 & 8 & 20 & 10 \\
\hline 3 & Eczemas & 8 & 12 & 20 & 10 \\
\hline 4 & Psoriasis & 6 & 4 & 10 & 5 \\
\hline 5 & Pigmented purpuric dermatoses & 6 & 4 & 10 & 5 \\
\hline 6 & Lichen planus & 3 & 5 & 8 & 4 \\
\hline 7 & Seborrheic keratosis & 4 & 4 & 8 & 4 \\
\hline 8 & Alopecia & 2 & 4 & 6 & 3 \\
\hline 9 & Macular amyloidosis & 2 & 2 & 4 & 2 \\
\hline 10 & Vitiligo & 2 & 2 & 4 & 2 \\
\hline 11 & Prurigo nodularis & 2 & 2 & 4 & 2 \\
\hline 12 & Perforating dermatosis & 1 & 1 & 2 & 1 \\
\hline 13 & Syringoma & 1 & 1 & 2 & 1 \\
\hline 14 & Urticaria & 1 & 1 & 2 & 1 \\
\hline 15 & Acne keloidalis nuchae & 1 & 1 & 2 & 1 \\
\hline
\end{tabular}

\section{References}

1. Davidson MB, Peters AL, Schriger DL. An alternative approach to the diagnosis of diabetes with a review of the literature. Diabetes Care 1995;8(7):1065-1071. DOI: 10.2337/diacare.18.7.1065.

2. The Expert Committee on the Diagnosis and Classification of Diabetes Mellitus. Report of the expert committee on the diagnosis and classification of diabetes mellitus. Diabetes Care 1997;20(7):1183-1197. DOI: 10.2337/diacare.20.7.1183.

3. Park K. Epidemiology of chronic non communicable diseases and conditions. In: Parks Textbook of preventive and social medicine. 21st ed., Jabalpur: Banarsi Das Bhanot Publishers; 2011. pp. 341-342.

4. Munichoodappa C. Epidemiology and burden of type 2 diabetes mellitus. In: Type 2 diabetes- The Indian scenario Jayaram BM, ed., Bangalore: Microlabs Ltd.; 2002. p. 13.

5. Kalus AA, Chien AJ, Olerud JE. Diabetes mellitus and other endocrine diseases. In: Wolff K, Goldsmith LA, Katz SL, et al., ed. Fitzpartick's dermatology in general medicine. 7th ed., USA (NY): McGraw-Hill; 2008. pp. 1461-1470.

6. Paron NG, Lambert PW. Cutaneous manifestations of diabetes mellitus. Prim Care 2000;27(2):371-383. DOI: 10.1016/s00954543(05)70201-3.
7. Sawhney M, Tutakne MA, Rajpathak SD, et al. Clinical study of diabetic dermoangiopathy. Indian J Dermatol Venerol Leprol 1990;56:18-21.

8. Mahajan S, Koranne RV, Sharma SK. Cutaneous manifestations of diabetes mellitus. Indian J Dermatol Venereol Leprol 2003;69(2):J05J08.

9. Nigam PK, Pande S. Pattern of dermatoses in diabetics. Indian J Dermatol Venerol Leprol 2003;69(2):83-85.

10. Nawaf A, Amr Z, Ashok KS, et al. Cutaneous manifestations of diabetes mellitus. Med Prine Pract 2006;15(6):427-430. DOI: 10.1159/000095488.

11. Rao GS, Pai GS. Cutaneous manifestations of diabetes mellitus. Indian J Dermatol Venereol Leprol 1997;63(4):232-234.

12. Romano G, Moretti G, Di Benedetto A, et al. Skin lesions in diabetes mellitus. Prevalence and clinical correlations. Diabet Res Clin Pract 1998;39:1016.

13. Al Mutairi N, Zaki A, Sharma AK, et al. Cutaneous manifestations of diabetes mellitus. Med Princ Pract 2006;J5(6):427-430. DOI: 10.1159/000095488.

14. Bhat YJ, Gupta V, Kudyar RP. Cutaneous manifestation of diabtes mellitus. Int J Diab Dev Ctries 2006;26(4):152-155. DOI: 10.4103/09733930.33180 . 
15. Yosipovitch G, Hodak E, Vardi P, et al. The prevalence of cutaneous manifestations in IDDM patients and their association with diabetes risk factors and microvascular complications. Diabetes Care 1998;21(4):506-509. DOI: 10.2337/diacare.21.4.506.

16. Ahmed M, Hussan I, Bhat MH, et al. Cutaneous manifestations of diabetes mellitus: a hospital based study in Kashmir, India. Egypt Dermatol Online J 2009;56(2):5.

17. Kahana M, Grossman E, Feinstein A, et al. Skin tags: a cutaneous marker for diabetes mellitus. Acta Derm Venerol 1987;67(2):175-177.
18. Thappa DM. Skin tags asmarkers of diabetes mellitus: an epidemiological study in India. J Dermatol 1995;22(10):729-731. DOI: 10.1111/j.1346-8138.1995.tb03910.x.

19. Puri N. A study on the cutaneous manifestations of diabetes mellitus. Our Dermatol Online 2012;3(2):83-86. DOI: 10.7241/ourd. 20122.17.

20. Goyal A, Raina S, Kaushal SS, et al. Pattern of cutaneous manifestations in diabetes mellitus. Indian J Dermatol 2010;55(1):39-41. DOI: 10.4103/0019-5154.60349. 